\title{
Assessment of long-term plasma exchange for familial hypercholesterolaemia
}

\author{
G R THOMPSON, N B MYANT, D KILPATRICK, * CELIA M OAKLEY, \\ $M$ J RAPHAEL, $\dagger$ R E STEINER
}

From the Medical Research Council Lipid Metabolism Unit, and the Departments of Clinical Cardiology, and Diagnostic Radiology, Royal Postgraduate Medical School, Hammersmith Hospital, London

SUMMARY The effectiveness of repeated plasma exchange with 2 to 4 litres of plasma protein fraction as long-term treatment for familial hypercholesterolaemia has been evaluated in six severely affected patients receiving conventional cholesterol lowering treatment. Cell-separator mediated exchange at monthly intervals for one to two years reduced mean serum cholesterol levels from $18.5 \mathrm{mmol} / 1$ ( 715 $\mathrm{mg} / \mathrm{dl})$ to $12.4 \mathrm{mmol} / \mathrm{l}(480 \mathrm{mg} / \mathrm{dl})$ in two female homozygotes but failed to influence xanthomata or prevent a two- to threefold increase in their left ventricular aortic systolic pressure gradients. More effective reduction of mean serum cholesterol levels from $15.7 \mathrm{mmol} / 1(608 \mathrm{mg} / \mathrm{dl})$ to $8.6 \mathrm{mmol} / 1$ ( $333 \mathrm{mg} / \mathrm{dl}$ ) in two male homozygotes by plasma exchange at fortnightly intervals for two to three years was accompanied by resolution of xanthomata and by stabilisation of aortocoronary lesions. In two male heterozygotes with angina, coronary angiographic appearances were unaltered or improved after one to two years of thrice-monthly plasma exchange, which reduced mean serum cholesterol levels from $6.4 \mathrm{mmol} / 1(248 \mathrm{mg} / \mathrm{dl})$ to $4.7 \mathrm{mmol} / 1(182 \mathrm{mg} / \mathrm{dl})$. We conclude that plasma exchange every one to two weeks, combined with oral nicotinic acid and/or cholestyramine, retards the rate of progression of atheroma in homozygotes and possibly induces regression in heterozygotes.

Familial hypercholesterolaemia is a dominantly inherited defect of beta- or low-density lipoprotein metabolism which affects approximately 1 in 500 persons in Britain ${ }^{1}$ and North America. ${ }^{2}$ The great majority of affected subjects are heterozygotes in whom the disorder is characterised by hyperbetalipoproteinaemia (type II hyperlipoproteinaemia) from birth, appearance of tendon xanthomata in early adult life, and the premature onset of coronary heart disease. Men have a 23 per cent risk of death from this cause before the age of $50 .^{3}$ The risk of premature death is even greater in the rare homozygotes who, as well as showing all the heterozygotes' features in an exaggerated form, in addition develop atheromatous involvement of the aortic root before puberty and show a pronounced resistance to cholesterol-lowering diets and drugs.

Four years ago we reported the feasibility of using plasma exchange to treat two patients with Present addresses: * Cardiovascular Research Institute, University of California, San Francisco.

† National Heart and Middlesex Hospitals, London.

Received for publication 11 October 1979 homozygous familial hypercholesterolaemia. ${ }^{4}$ Since then we have treated a further four patients, two homozygotes and two heterozygotes, and have performed almost 300 plasma exchanges in the process. This paper provides evidence that the progressive accumulation of cholesterol in skin, tendons, and arterial wall which accompanies severe familial hypercholesterolaemia can be either arrested or partially reversed by combining conventional hypocholesterolaemic drug treatment with long-term plasma exchange. Some of the data have been published previously in abstract form..$^{56}$

\section{Subjects and methods}

Clinical details of the six patients are shown in Table 1 and the duration and frequency of plasma exchange in Table 2. Both female homozygotes underwent this procedure at approximately monthly intervals, as previously described. ${ }^{4}$ This was discontinued in case 1 after two years for social reasons; she subsequently underwent an aortocoronary bypass but died after operation. Plasma 
Table 1 Clinical details of patients with familial hypercholesterolaemia undergoing plasma exchange

\begin{tabular}{|c|c|c|c|c|c|c|c|}
\hline \multirow{2}{*}{ Genotype } & \multirow{2}{*}{ Case no. } & \multirow{2}{*}{ Sex } & \multirow{2}{*}{ Age } & \multicolumn{3}{|c|}{ Serum lipids $(\mathrm{mmol} / \mathrm{l})^{\star}$} & \multirow{2}{*}{ Drug treatment } \\
\hline & & & & $T C$ & $T G$ & $H D L$ chol & \\
\hline $\begin{array}{l}\text { Homozygote } \\
\text { Heterozygote }\end{array}$ & $\begin{array}{l}1 \\
2 \\
3 \\
4 \\
5 \\
6\end{array}$ & $\begin{array}{l}\mathrm{F} \\
\mathrm{F} \\
\mathrm{M} \\
\mathrm{M} \\
\mathrm{M}\end{array}$ & $\begin{array}{l}23 \\
26 \\
25 \\
15 \\
31 \\
47\end{array}$ & $\begin{array}{r}21.0 \\
16.1 \\
15.5 \\
15.8 \\
6.2 \\
6.5\end{array}$ & $\begin{array}{l}0 \cdot 49 \\
2 \cdot 21 \\
0.90 \\
1 \cdot 10 \\
1 \cdot 47 \\
1 \cdot 67\end{array}$ & $\begin{array}{l}0 \cdot 83 \\
0 \cdot 67 \\
0 \cdot 72 \\
0 \cdot 65 \\
0 \cdot 67 \\
0 \cdot 62\end{array}$ & $\begin{array}{l}\text { Resin + CPIB or NA } \\
\text { Resin + CPIB, or NA or Neo } \\
\text { Resin + NA } \\
\text { Resin } \\
\text { Resin + CPIB } \\
\text { Resin }\end{array}$ \\
\hline
\end{tabular}

* While on low cholesterol diet and drug treatment, before starting plasma exchange.

TC, total cholesterol; TG, triglyceride; HDL chol, high-density lipoprotein cholesterol; Resin, cholestyramine 16 to 36 g/day; CPIB, clofibrate $2 \mathrm{~g}$ /day; NA, nicotinic acid 2 to $5 \mathrm{~g} /$ day; Neo, neomycin $2 \mathrm{~g} /$ day.

Conversion: SI to traditional units; Cholesterol $1 \mathrm{mmol} / 1 \approx 38.7 \mathrm{mg} / \mathrm{dl}$; triglyceride $1 \mathrm{mmol} / 1 \approx 88.5 \mathrm{mg} / \mathrm{dl}$.

exchange was discontinued in case 2 after 10 months because of increasing difficulty with venous access and she later underwent a portacaval shunt, as reported elsewhere. ${ }^{7}$ She has since had an aortic valve replacement and triple aortocoronary bypass grafts. Both male homozygotes (cases 3 and 4) have been undergoing plasma exchange at one to two weekly intervals for two and three years, respectively, and are continuing to do so. Both are asymptomatic but each had sustained the loss of a homozygous teenage sib before starting plasma exchange. Both male heterozygotes presented with severe angina. One (case 5) underwent a successful aortocoronary bypass operation after 12 months of plasma exchange, whereas the second heterozygote (case 6) had sufficient relief from angina after nearly two years of plasma exchange to justify postponement of surgical intervention.

Plasma exchange was performed with an Aminco Celltrifuge on an outpatient basis, as described elsewhere. ${ }^{489}$ Each patient's plasma was exchanged with 2 to 4 litres plasma protein fraction, anticoagulation being maintained with heparin. No significant complications have occurred except for some localised phlebosclerosis at venepuncture sites.

Clinical progress has been monitored by serial cineangiographic studies of the aorta and coronary arteries and measurement of left ventricularaortic systolic gradients. By simultaneously projecting pre- and post-treatment films, paired frames were matched both anatomically and for phase of cardiac cycle and then made into composite slides. These were analysed "blind" by an independent observer, using a projection microscope to obtain $\times 10$ magnified images on a ground-glass screen, which were then traced and measured.

Serum cholesterol and triglyceride concentrations were determined routinely ${ }^{10}$ before each plasma exchange and, in some instances, immediately afterwards. Serum high-density lipoprotein cholesterol was determined as previously described. ${ }^{4}$ The mean serum cholesterol level between exchanges was calculated by integrating the area beneath the rebound curve joining each post-exchange value to the subsequent pre-exchange value, and then dividing by the time interval between exchanges.

In four patients the faecal excretion of neutral sterols and bile acids ${ }^{11} 12$ was measured during the week before and the week after a single plasma exchange, at a time when they were in-patients in the Metabolic Unit, off all hypocholesterolaemic drugs and on a constant intake of dietary fat $(P: S$ ratio $2: 1)$, cholesterol $(200 \mathrm{mg} /$ day $)$, and chromic oxide ( $1.5 \mathrm{~g} /$ day), which was given as a nonabsorbable marker.

\section{Results}

CHANGES IN SERUM CHOLESTEROL

During each procedure there was a rapid decrease

Table 2 Overall serum cholesterol levels throughout period of plasma exchange

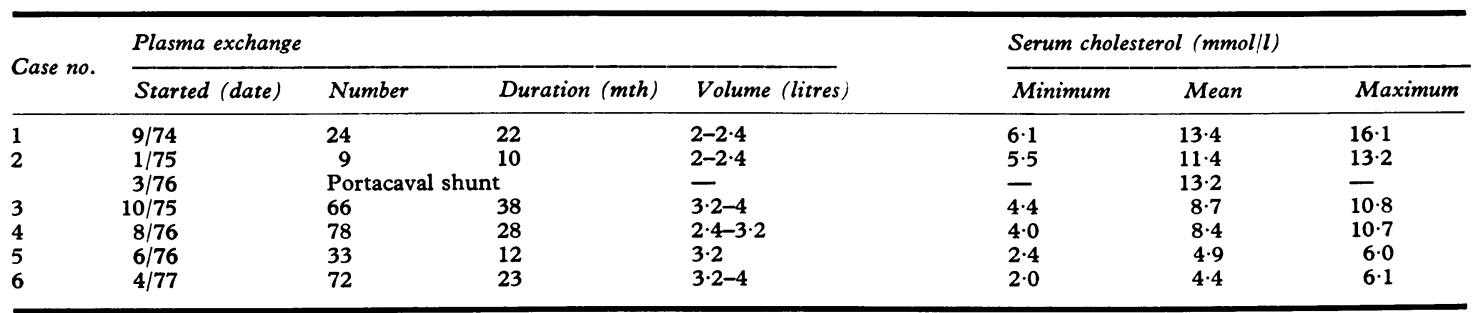


Fig. 1 Serum cholesterol levels showing mean (solid line), maximum (upper border of stippled area), and minimum (lower border of stippled area) values observed in two homozygotes undergoing regular plasma exchange. The volume in litres of plasma protein fraction used and the number of exchanges per month are indicated above, together with the daily dosage of hypocholesterolaemic drugs administered. NA, nicotinic acid; $C P I B$, clofibrate. $D L$, case 4; $R W$, case 3.

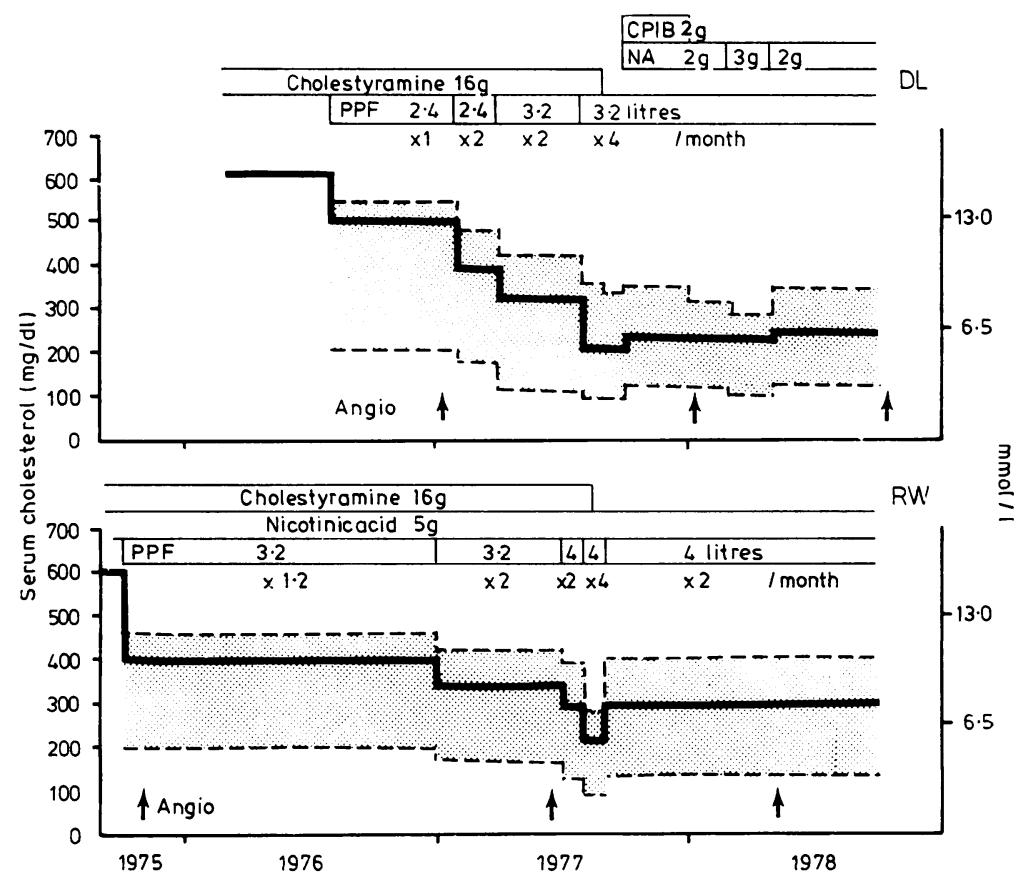

(35 mg/dl), respectively, during the second week.

Long-term fluctuations in serum cholesterol in patients undergoing plasma exchange at regular intervals can best be described in terms of the maximum or pre-exchange value, the minimum or post-exchange value, and the mean level between exchanges. These results are summarised in Table 2 . The influence of the frequency and volume of plasma exchanged and of concomitant drug treatment is illustrated in Fig. 1 and 2.
Fig. 2 Serum cholesterol levels in two heterozygotes undergoing regular plasma exchange. AS, case $6 ; \mathfrak{F H}$, case 5 .

Explanation of legend as for Fig. 1. Neo, neomycin.

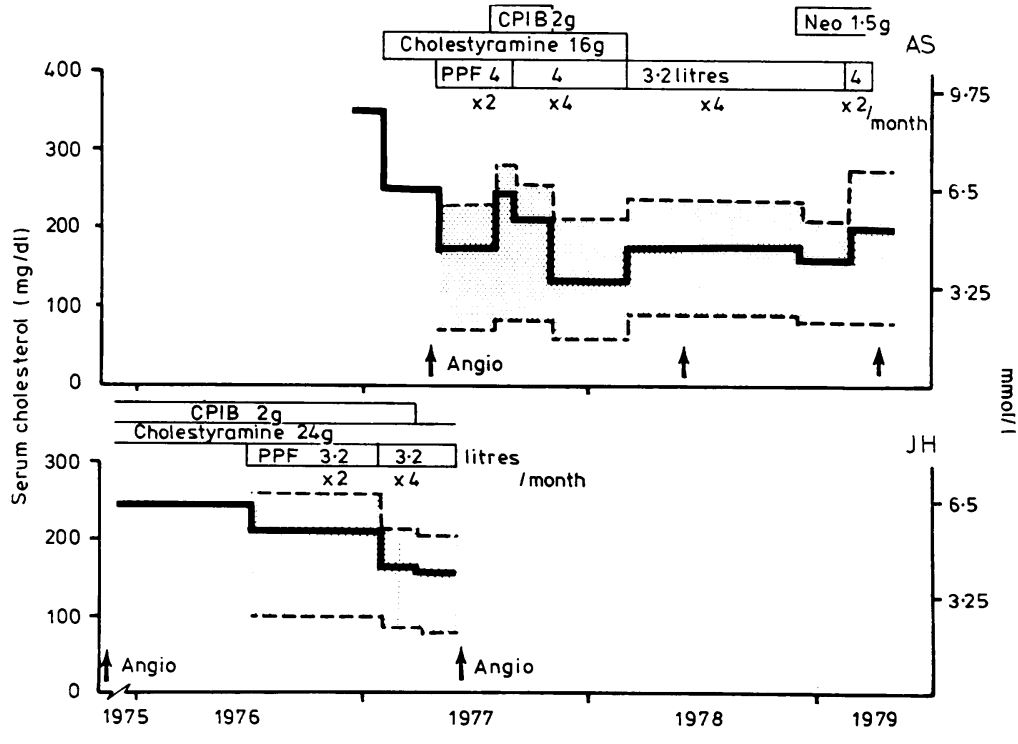


As shown in Fig. 1 the mean serum cholesterol in homozygote case 3 was reduced to less than 60 per cent of the level achieved by drug treatment alone when the latter was supplemented by 4.0 litre exchanges at fortnightly intervals. Similarly, $3 \cdot 2$ litre exchanges at weekly intervals reduced the mean serum cholesterol in homozygote case 4 by more than 50 per cent. Discontinuation of cholestyramine had no effect on serum cholesterol levels in either patient provided that nicotinic acid treatment was maintained.

Fig. 2 shows the results in the two heterozygotes. The mean serum cholesterol concentration in case 5 decreased from $6.2 \mathrm{mmol} / 1(240 \mathrm{mg} / \mathrm{dl})$ on cholestyramine and clofibrate, to $4.1 \mathrm{mmol} / 1(160 \mathrm{mg} / \mathrm{dl})$ during weekly $3 \cdot 2$ litre plasma exchanges. Case 6 presented with a serum cholesterol of $9 \mathrm{mmol} / 1$ $(350 \mathrm{mg} / \mathrm{dl})$, which decreased to $6.5 \mathrm{mmol} / 1$ (250 $\mathrm{mg} / \mathrm{dl}$ ) on cholestyramine and to $3.5 \mathrm{mmol} / 1$ $(135 \mathrm{mg} / \mathrm{dl})$ when administration of the latter was accompanied by weekly 4.0 litre plasma exchanges. Addition of clofibrate caused a sharp increase in serum cholesterol levels in case 6 .

\section{CHANGES IN XANTHOMATA AND FAECAI}

\section{STEROID EXCRETION}

Combined treatment with plasma exchange and nicotinic acid for two to three years has been accompanied by almost complete resolution of the cutaneous xanthomata of homozygotes cases 3 and 4, and by a pronounced reduction in the size of their tendon xanthomata, as illustrated in Fig. 3 and 4. No such changes were observed in cases 1 and 2 .

Faecal excretion of neutral sterols and bile acids before and after a single plasma exchange in two homozygotes and two heterozygotes is shown in Table 3. Mean neutral sterol excretion increased from 613 to $767 \mathrm{mg} /$ day during the week after plasma exchange, and bile acid excretion decreased

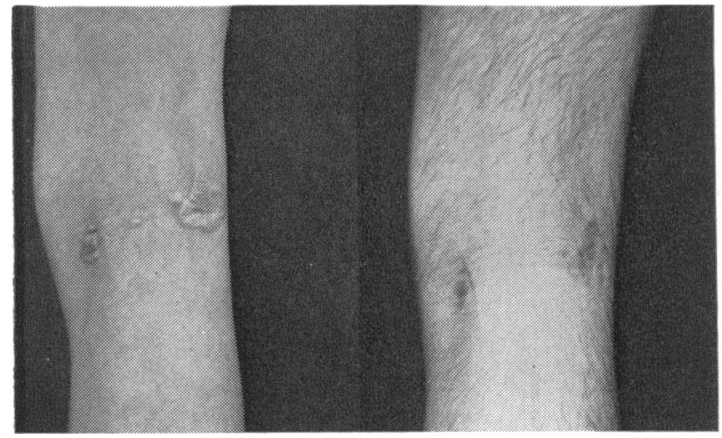

Fig. 3 Cutaneous xanthomata in the right popliteal fossa of a homozygote (case 4) before and after two years of plasma exchange.

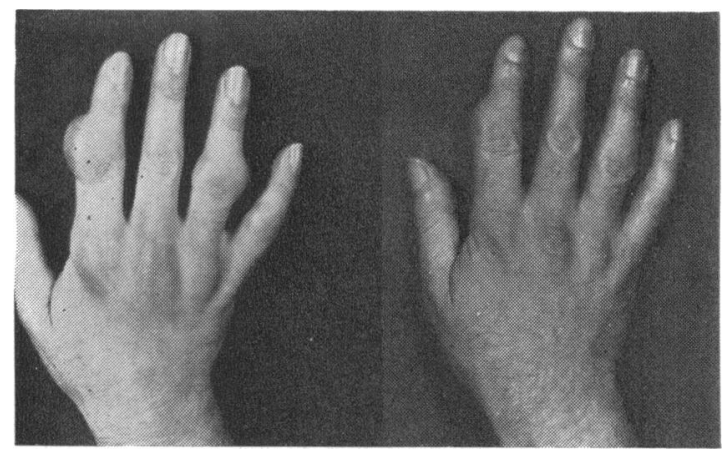

Fig. 4 Tendon xanthomata over the interphalangeal and metacarpo-phalangeal joints of a homozygote (case 3) before and after three years of plasma exhange.

from 498 to $420 \mathrm{mg} /$ day. However, the only statistically significant difference was an increase in neutral sterol excretion in homozygote case 3 after a 4.6 litre exchange. Total faecal steroids averaged $1111 \mathrm{mg} /$ day before and $1187 \mathrm{mg} /$ day after plasma exchange.

\section{ANGIOGRAPHIC APPEARANCES AND AORTIC GRADIENTS}

At least two complete angiographic studies were performed in three of the homozygotes. As illustrated in Fig. 5 (upper panel), the irregular and narrowed appearances of the supravalvular portion of the aorta and the right coronary ostium in case 3 have not changed during nearly three years of plasma exchange, nor was there any change in the aortograms of case 4 (Fig. 5, middle panel). However, the second study on case 2 showed left ventricular hypertrophy and a decrease in the mobility of her aortic valve cusps (Fig. 5, lower panel). Measurement of the ratio of the diameter of the narrowed aortic roots to that of adjacent unaffected segments, as shown in Table 4, confirmed the lack of change in

Table 3 Faecal steroids in patients with familial hypercholesterolaemia during week before and week after plasma exchange with plasma protein fraction (PPF)

\begin{tabular}{|c|c|c|c|c|c|}
\hline \multirow{2}{*}{$\begin{array}{l}\text { Case } \\
\text { no. }\end{array}$} & \multirow{2}{*}{$\begin{array}{l}\text { Volume } \\
\text { of PPF } \\
\text { (litres) }\end{array}$} & \multicolumn{2}{|c|}{ Bile acids (mg/day)* } & \multicolumn{2}{|c|}{ Neutral sterols (mg/day)* } \\
\hline & & Before & After & Before & After \\
\hline $\begin{array}{l}3 \\
4 \\
5 \\
6 \\
\text { Mean }\end{array}$ & $\begin{array}{l}4 \cdot 6 \\
2 \cdot 0 \\
4 \cdot 0 \\
4 \cdot 0 \\
3 \cdot 65\end{array}$ & $\begin{array}{l}551 \pm 58 \\
577 \pm 95 \\
281 \pm 31 \\
583 \pm 57 \\
498 \pm 73\end{array}$ & $\begin{array}{l}531 \pm 32 \\
372 \pm 8 \\
321 \pm 51 \\
454 \pm 89 \\
420 \pm 46\end{array}$ & $\begin{array}{l}712 \pm 40 \dagger \\
266 \pm 36 \\
621 \pm 35 \\
851 \pm 32 \\
631 \pm 125\end{array}$ & $\begin{aligned} 1051 & \pm 108 t \\
186 & \pm 13 \\
881 & \pm 81 \\
950 & \pm 166 \\
767 & \pm 197\end{aligned}$ \\
\hline
\end{tabular}

$\star$ Values in each patient represent the mean $\pm S E$ of determinations on three to five samples collected during the week before and the week after plasma exchange, corrected for recovery of chromic oxide.

$t \mathrm{p}<0.01$ (Student's t test). 

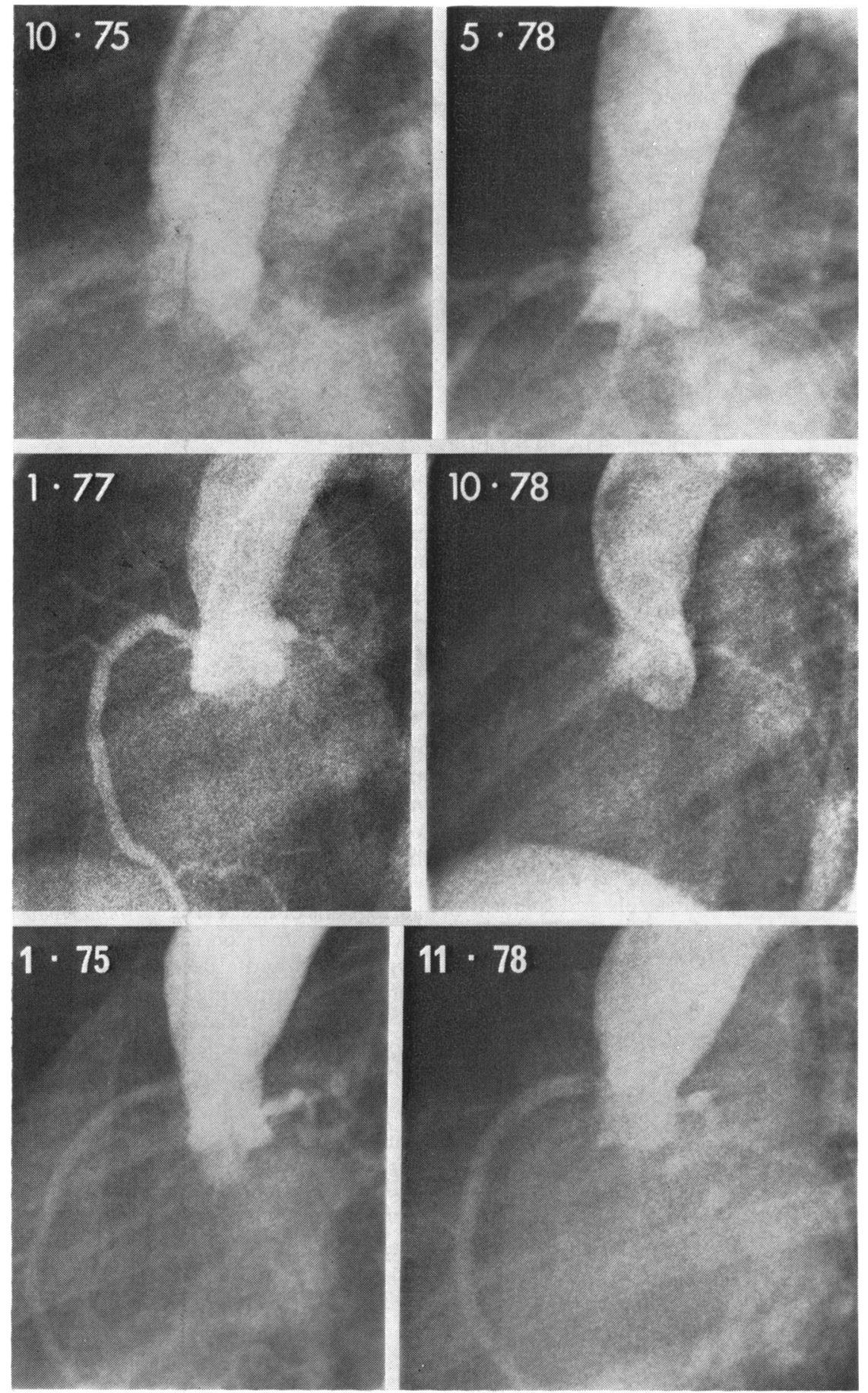

Fig. 5 Upper panel: Aortograms in homozygote case 3 showing irregular contour and narrowing of the aortic root and right coronary ostial stricture before (10/75) and after (5/78) 31 months of plasma exchange. Middle panel: Aortograms in case 4 showing narrowed aortic root before (1/77) and after (10/78) 21 months of plasma exchange. Lower panel: Aortogram in case 2 showing narrowed aortic root before (1/75) and after (11/78) 10 months of plasma'. exchange followed by a portacaval shunt. Note the altered appearance of the aortic sinuses during the second study. 
any patient (excluding case 1 , in whom an initial aortogram was not done).

The peak systolic gradient between the left ventricle and aorta was measured on at least two occasions in all four homozygotes, the results being shown in Table 4. Substantial increases occurred in cases 1 and 2 over periods of 26 and 46 months, in contrast to cases 3 and 4 in whom there was little change during 31 and 21 months, respectively. Mean serum cholesterol levels were considerably higher in cases 1 and 2 during the interval between angiograms $(11.4$ to $13.4 \mathrm{mmol} / 1$ or 440 to $520 \mathrm{mg} /$ dl) than in cases 3 and $4(8.4$ to $8.7 \mathrm{mmol} / 1$ or 325 to $337 \mathrm{mg} / \mathrm{dl}$ ), as shown in Table 2 .

Each of the heterozygotes underwent two angiographic studies; both patients had normal aortograms but each showed bilateral atheromatous involvement of the coronary arteries. The appearances were unchanged in case 5 after nine months of cholestyramine alone followed by a year of plasma exchange (Fig. 6, upper panel). However, there was an apparent increase in the calibre of a stricture of the anterior descending branch of the left coronary artery in case 6 after a year of plasma exchange (Fig. 6, middle panel). There was no further change in this lesion after a second year but a decrease in the degree of dilatation of his ectatic right coronary artery proximal to the site of its occlusion was noted (Fig. 6, lower panel). Mean serum cholesterol levels were 4.4 to $4.9 \mathrm{mmol} / 1$ (170 to $190 \mathrm{mg} / \mathrm{dl})$ in the two heterozygotes between plasma exchanges (Table 2).

\section{Discussion}

This paper analyses four years' experience with plasma exchange in the treatment of severe familial hypercholesterolaemia, the term severe encompassing both homozygotes and heterozygotes with coronary heart disease. The fact that six patients have successfully undergone a total of almost 300

Table 4 Left ventricular-aortic systolic gradients and aortographic appearances in homozygotes undergoing plasma exchange

\begin{tabular}{lrcc}
\hline Case no. & Date of angiogram & $\begin{array}{c}\text { Gradient } \\
(\mathrm{mmHg})\end{array}$ & $\begin{array}{c}\text { Aortic } \\
\text { ratio }\end{array}$ \\
\hline 1 & $9 / 74$ & 35 & - \\
2 & $11 / 76$ & 75 & - \\
3 & $1 / 75$ & 34 & 0.59 \\
& $11 / 78$ & 130 & 0.58 \\
4 & $10 / 75$ & 40 & 0.73 \\
& $5 / 78$ & 50 & 0.71 \\
& $1 / 77$ & 19 & 0.67 \\
\hline
\end{tabular}

* Diameter of narrowed lumen

Diameter of adjacent, normal lumen plasma exchanges without serious complications attests both to the safety of the procedure and its acceptability to such individuals. In particular there was no instance of bacterial endocarditis in any of the homozygotes, whose diseased aortic valves renders them vulnerable to this risk. The reliability of the equipment used and the suitability of plasma protein fraction as an exchange fluid have greatly facilitated carrying out repeated plasma exchanges over prolonged periods. A commitment to treating homozygotes by this means should not prove too great a liability to any major centre equipped with a cell-separator because of the small number of patients likely to be involved. Plasma exchange is heavily dependent upon the availability of plasma protein fraction, however, and for this reason, we restrict its use in the far commoner heterozygotes to those with severe angina.

The use of plasma exchange to treat familial hypercholesterolaemia is based upon the premise that defective catabolism of low-density lipoprotein is largely responsible for the hypercholesterolaemia. ${ }^{13} 14$ Physical removal of low-density lipoprotein from the intravascular compartment is therefore a logical approach, especially in homozygotes who respond poorly to drugs such as cholestyramine, which act by promoting lowdensity lipoprotein catabolism. ${ }^{15}$ It is relevant that plasma exchange does not appear to stimulate lowdensity lipoprotein-apoB synthesis, especially since this is already somewhat higher than normal in homozygotes. ${ }^{16}$ Furthermore, we found no evidence that plasma exchange caused any net increase or decrease in faecal steroid excretion, which is the normal pathway for removal of cholesterol; however, because these were non-steady-state studies it was not possible to deduce whether there was any change in cholesterol synthesis.

Streja et al. ${ }^{17}$ recently described an association between coronary heart disease and reduced levels of high-density lipoprotein cholesterol in familial hypercholesterolaemia. Since plasma exchange decreases high-density lipoprotein levels still further it might seem to be deleterious. However, during the subsequent week the high-density lipoprotein (HDL) cholesterol concentration increases proportionally faster than the low-density lipoprotein (LDL) cholesterol and the HDL:LDL cholesterol ratio rises. ${ }^{4}$ If one accepts that this ratio is an even more sensitive index of coronary heart disease risk than is high-density lipoprotein cholesterol, ${ }^{17}$ then plasma exchange can be regarded as having a favourable effect, rather than the reverse.

Our data suggest that plasma exchange at monthly intervals does not control hypercholesterolaemia sufficiently well in homozygotes to prevent progres- 

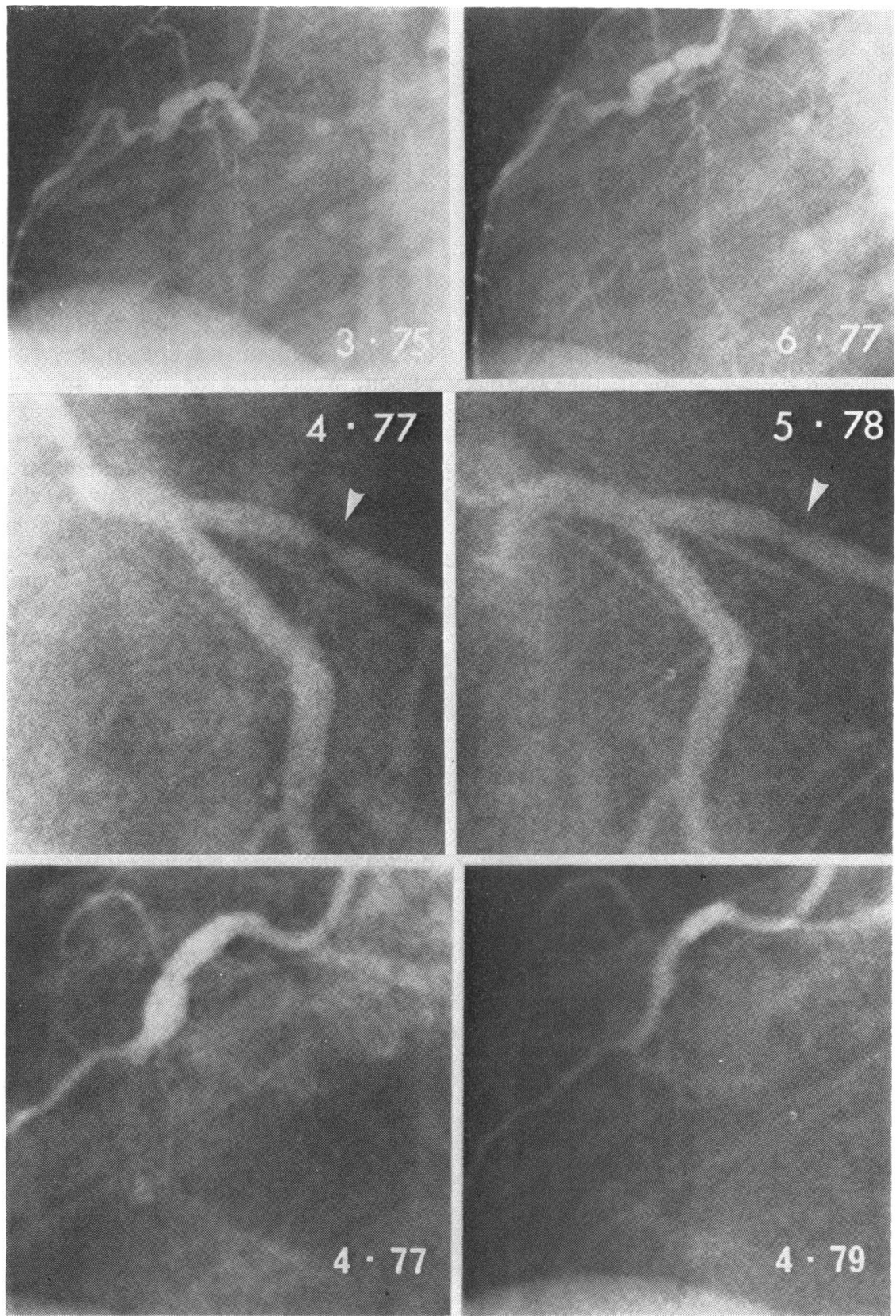

Fig. 6 Upper panel: Coronary angiograms in heterozygote case 5 showing dilatation of right coronary artery proximal to site of occlusion before (3/75) and after (6/77) a period of conventional therapy followed by a year of plasma exchange. Middle panel: Coronary angiogram in heterozygote case 6 shouing a stricture of the anterior descending branch of the left coronary artery (arrowed), before (4/77) and after (5/78) 13 months of plasma exchange. Lower panel: Coronary angiogram in heterozygote case 6 showing degree of dilatation of a partially occluded right coronary artery before (4/77) and after (4/79) two years of plasma exchange. 
sion of their disease. Both female patients developed a substantial increase in the systolic gradient between their left ventricle and aorta at a time when their serum cholesterol levels averaged about $13 \mathrm{mmol} / 1(500 \mathrm{mg} / \mathrm{dl})$. It seems probable that a rising aortic gradient reflects progressive infiltration of the valve cusps, either by atheroma, ${ }^{18}$ or fibrosis. ${ }^{1920}$ The threefold increase observed in case 2 occurred without any change in the degree of narrowing of the supravalvular part of her aorta and she was later found at operation to have a much fibrosed aortic valve. This was in spite of her having undergone a portacaval shunt three years previously which, unfortunately, resulted in only a transient fall in serum cholesterol. ${ }^{\text {? }}$

The findings in the two male homozygotes currently on plasma exchange are more encouraging. More effective reduction of hypercholesterolaemia by a combination of nicotinic acid and plasma exchange at one to two weekly intervals, using 3.2 to 4.0 litres of plasma protein fraction on each occasion, resulted in regression of both cutaneous and tendon xanthomata, indicating mobilisation of tissue cholesterol at these sites. Angiographic and haemodynamic studies suggest that their aortic lesions have not progressed over the past two to three years, during which their serum cholesterol levels averaged $8.6 \mathrm{mmol} / 1(333 \mathrm{mg} / \mathrm{dl})$. Similarly encouraging results in a homozygote have been reported recently by Berger et al. ${ }^{20}$ who also found cholestyramine to be ineffective in slowing down the post-exchange rebound of serum cholesterol. The inability of cholestyramine to control hypercholesterolaemia in homozygotes is well documented ${ }^{2122}$ and contrasts with its effectiveness in heterozygotes.

Apparent angiographic improvement was observed in one of the heterozygotes (case 6 ), in whom there was an increase in the calibre of a stricture of the anterior descending branch of the left coronary artery after one year of weekly plasma exchange and cholestyramine, during which his serum cholesterol averaged $4.4 \mathrm{mmol} / 1(170 \mathrm{mg} / \mathrm{dl})$, decreasing to $2.0 \mathrm{mmol} / 1 \quad(77 \mathrm{mg} / \mathrm{dl})$ immediately after each procedure, and seldom rising above $6.5 \mathrm{mmol} / 1$ $(250 \mathrm{mg} / \mathrm{dl})$; the significance of the decrease in the degree of ectasia of his right coronary artery is difficult to evaluate in the absence of any information on blood flow. Spontaneous resolution of such strictures has been recorded, but not in patients with familial hypercholesterolaemia. ${ }^{23}$ However, regression of early femoral atherosclerosis ${ }^{24}$ and nonprogression of advanced coronary lesions ${ }^{25}$ have recently been claimed in heterozygotes whose hypercholesterolaemia was effectively controlled by conventional means. The even better control achieved by long-term plasma exchange provides a potential means of establishing whether rigorous reduction of serum cholesterol really can induce regression of coronary atherosclerosis in this situation. The advantage of small-scale, serial angiographic studies in answering this key question is that they assess the effects of treatment on atheromatous lesions more directly than do clinical trials, and are also shorter and less expensive; their main disadvantage is the difficulty of obtaining matching views and interpreting angiographic change. ${ }^{26}$

Although the arterial lesions of homozygous familial hypercholesterolaemia are indistinguishable histologically from atherosclerosis, except perhaps for the excessive number of foam cells present and the intensity of cholesterol deposition, ${ }^{27} 28$ anatomically their distribution is distinctly unusual, with a unique predilection for the aortic valve, sinuses of Valsalva, and the aortic root. The supravalvular lesion also occurs in heterozygotes but without involvement of the aortic valve. ${ }^{29}$ Coronary angiography reveals a high proportion of patients with ostial stenosis and triple vessel or left main stem disease. ${ }^{30}$ Presumably these features reflect the hypercholesterolaemic basis of the underlying atheroma, as opposed to the multifactorial origins of coronary heart disease as found in the general population. Thus, any evidence of a beneficial effect of reducing serum cholesterol on the premature and severe lesions seen in familial hypercholesterolaemia should be interpreted with caution when considered in the wider context of atherosclerosis at large.

We thank the nurses who have helped run the cellseparator; Dr E Jepson for referring case 3; Saro Niththyananthan for determining faecal steroids; David Hawtin for making composite films of the angiograms and Hilary Stanbrook for analysing them. We also acknowledge the vital role played by Sir William Maycock and the Blood Products Laboratory, Elstree, Herts, in providing us with a constant supply of plasma protein fraction.

\section{References}

1 Slack J. Early metabolic prediction in adults. In: McDonald CL, Goodwin JF, Resnekov V, eds. Very early recognition of coronary heart disease. Excerpta Medica International Congress Series No. 435. Amsterdam: Excerpta Medica, 1978: 11-17.

2 Brown MS, Goldstein JL. Familial hypercholesterolemia: a genetic defect in the low density lipoprotein receptor. $N$ Engl f Med 1976; 294: 1386-90.

3 Slack J. Risk of ischaemic heart disease in familial hyperlipoproteinaemic states.Lancet 1969; ii : 1380-2. 
4 Thompson GR, Lowenthal R, Myant NB. Plasma exchange in the management of homozygous familial hypercholesterolaemia. Lancet 1975; i: 120811.

5 Thompson GR, Kilpatrick D, Raphael M, Oakley C, Myant NB. Use of plasma exchange to induce regression of atheroma in familial hypercholesterolaemia (abstract) Eur f Clin Invest 1977; 7: 233.

6 Thompson G, Kilpatrick D, Oakley C, Steiner R, Myant N. Reversal of cholesterol accumulation in familial hypercholesterolemia by long-term plasma exchange (abstract). Circulation 1978; 57 \& 58, suppl II: 171.

7 Soutar AK, Myant NB, Thompson GR. Simultaneous measurement of apolipoprotein B turnover in very-low and low-density lipoproteins in familial hypercholesterolaemia. Atherosclerosis 1977; 28 : 24756.

8 Thompson GR. Management of familial hypercholesterolaemia and new approaches to the treatment of atherosclerosis. In: Paoletti R, Gotto AM, eds. Atherosclerosis reviews Vol 5. New York: Raven Press, 1979: 67-90.

9 Thompson GR. Use of plasma-protein fraction in plasma exchange (letter). Lancet 1976; ii: 263.

10 Lewis B, Chait A, Wootton IDP, et al. Frequency of risk factors for ischaemic heart-disease in a healthy British population, with particular reference to serum-lipoprotein level. Lancet 1974; i: 146-6.

11 Miettinen JA, Ahrens EH, Grundy SM. Quantitative isolation and gas-liquid chromatographic analysis of total dietary and fecal neutral steroids. $f$ Lipid Res 1965; 6: 411-24.

12 Grundy SM, Ahrens EH Jr, Miettinen TA. Quantitative isolation and gas-liquid chromatographic analysis of total fecal bile acids. $\mathcal{F}$ Lipid Res 1965; 6: 397-410.

13 Langer T, Strober W, Levy RI. The metabolism of low density lipoprotein in familial type II hyperlipoproteinemia. $\mathcal{F}$ Clin Invest 1972; 51: 1528-36.

14 Myant NB. The metabolic lesion in familial hypercholesteremia. In: Polonovski J, ed. Cholesterol metabolism and lipolytic enzymes. New York: Masson Publishing USA, 1977: 39-52.

15 Levy RI, Langer T. Hypolipidemic drugs and lipoprotein metabolism. Adv Exp Med Biol 1972; 26: 155-63.

16 Soutar AK, Myant NB, Thompson GR. Metabolism of apolipoprotein-B-containing lipoproteins in familial hypercholesterolaemia. Effects of plasma exchange. Atherosclerosis 1979; 32: 315-25.

17 Streja D, Steiner G, Kwiterovich PO Jr. Plasma high-density lipoproteins and ischemic heart disease studies in a large kindred with familial hypercholesterolemia. Ann Intern Med 1978; 89: 871-80.
18 Rigdon RH, Willeford G. Sudden death during childhood with xanthoma tuberosum: review of literature and report of case. $\mathcal{F} A M A 1950 ; 142$ : 1268-71.

19 Cook CD, Smith HL, Giesen CW, Birdez GL. Xanthoma tuberosum, aortic stenosis, coronary sclerosis and angina pectoris. Am $\mathcal{F}$ Dis Child 1947; 73: 326-33.

20 Berger GMB, Miller JL, Bonnici F, Joffe HS, Dubovsky DW. Continuous flow plasma exchange in the treatment of homozygous familial hypercholesterolemia. Am $\mathcal{f}$ Med 1976; 65: 243-51.

21 Khachadurian AK. Cholestyramine therapy in patients homozygous for familial hypercholesterolemia. $\mathcal{F}$ Athero Res 1968; 8: 177-88.

22 Moutafis CD, Myant NB. The metabolism of cholesterol in two hypercholesterolaemic patients treated with cholestyramine. Clin Sci 1969; 37: 443-54.

23 Landman J, Kolsters W, Bruschke AVG. Regression of coronary artery obstructions demonstrated by coronary arteriography. Eur $\mathcal{F}$ Cardiol 1976; 4: 475-9.

24 Barndt R Jr, Blankenhorn DH, Crawford DW, Brooks SH. Regression and progression of early femoral atherosclerosis in treated hyperlipoproteinemic patients. Ann Intern Med 1977; 86: 139-46.

25 Kuo PT, Hayase K, Kostis JB, Moreyra AE. Use of

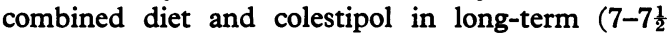
years) treatment of patients with type II hyperlipoproteinaemia. Circulation 1979; 59: 199-211.

26 Blankenhorn AH, Sanmarco ME. Angiography for study of lipid-lowering therapy (editorial). Circulation 1979; 59: 212-4.

27 Barr DP, Rothbard S, Eder HA. Atherosclerosis and aortic stenosis in hypercholesteremic xanthomatosis. $\mathcal{F} A M A$ 1954; 156: 943-7.

28 Fredrickson DS, Levy RI. Familial hyperlipoproteinemia. In: Stanbury JB, Wyngaarden JB, Fredrickson DS, eds. The metabolic basis of inherited disease 3rd ed. New York: McGraw-Hill, 1972: 545-614.

29 Roberts WC, Ferrans VJ, Levy RI, Fredrickson DS. Cardiovascular pathology in hyperlipoproteinemia. Anatomic observations in 42 necroscopy patients with normal or abnormal serum lipoprotein patterns. Am f Cardiol 1973; 31: 557-70.

30 Bloch A, Dinsmore RE, Lees RS. Coronary angiographic findings in Type II and Type IV hyperlipoproteinaemia. Lancet 1976; i: 928-30.

Requests for reprints to $\mathrm{Dr} G \mathrm{R}$ Thompson, MRC Lipid Metabolism Unit, Hammersmith Hospital, Du Cane Road, London W12 0HS. 